\title{
Developing a framework for block chain adoption using TOE model
}

\author{
Hany. Hanna \\ Mai.H. Haroun \\ Nermin Gohar \\ Logistics of Supply Chain Department, College of International Transport and Logistics \\ Arab Academy for Science, Technology and Maritime Transport, Alexandria, Egypt
}

\section{Keywords}

Block chain Adoption; Supply chain management, Technology-Organization -Environment (TOE).

\begin{abstract}
The purpose -Block chain has numerous benefits such as decentralization, persistency, anonymity, and auditability. Although a number of studies focus on using the block chain technology in various application aspects, there is not a specific previous study focus on the block chain technology in both technological context and business organizations through the supply chain flows. Therefore, the purpose of this paper empathizes how using the technological theories and block chain technologies through the supply chain will affect it as a whole; in addition to such adoption is very rare to be represented especially in developing countries as this part is fulfilled by our paper research.

Design/methodology/approach - Data were collected through a self-created questionnaire a number of 427 respondents were included in the questionnaire analysis which were collected from employees of supply chain and logistics companies.

Practical implications - The findings reveal the importance after conducting regression analysis and SEM, it was observed that reducing complexity and lowering supply chain investment costs associated with traditional supply chain transactions were some of the key drivers for block chain adoption, as well as a desire to benefit from enhanced compatibility and regulatory support. However, achieving security is considered as the main and most important driver.

Originality/value -This research provides an insight to understand the significant dimensions of block chain adoption, where the dimensions of security, regulatory support, competitive pressure, compatibility, and complexity are found to have a significant effect on block chain adoption.
\end{abstract}

Corresponding author: Mai.H. Haroun

Email addresses for the corresponding author: maiharoun.mo@gmail.com

First submission received: $16^{\text {th }}$ June 2020

Revised submission received: $28^{\text {th }}$ September 2020

Accepted: $2^{\text {nd }}$ October 2020

Introduction

Supply chain management has become an important aspect for the increasing demand of logistics companies after having that dynamic environment and globalization. New technologies can overcome the challenges imposed due to such globalization and increasing demand of logistics services. Block chain is one of the trending technologies nowadays that could heavily help overcoming the challenges that companies are facing, meanwhile, block chain adoption is not an easy issue specially in the developing countries. In addition, few researches had discussed block chain adoption especially from the quantitative vision of the technology rather than the qualitative opinion.

Therefore, this research comes to fill such gap in the literature and study block chain adoption and the factors affecting it. This research is divided into several sections, where the first one is represented in the current introduction for the research. The second section presents a review of the previous studies related to block chain adoption and the factors that could affect it. The third section presents the research methodology for the current research, while the fourth section displays the results and findings for the empirical study. Finally, a conclusion is derived for this research in the fifth section. 


\section{Literature Review}

Block chain in its simplest form is a shared digital ledger which allows users in a peer-to-peer network to verify and store records. Block chain represents a new way to access and trust data communicated over the internet. Block chain transactions can include the exchange of data such as personal identification records, and assets such as 'tokens' and digital currency. Instead of keeping data centralized in a traditional ledger, these new digital systems use independent computers, often referred to as 'nodes', to record, synchronize and share individual transactions in their respective electronic ledgers.

The general idea behind supply chain management (SCM) is to manage the flow of goods, services, and information in an effective way in order to achieve high performance and decrease risks (Tan, 2001). There are billions of products being manufactured every day globally, through complex supply chains that extend to all parts of the world. However, there is very little knowledge of how, when and where these products were originated, manufactured, and used through their life cycle. Day by day, supply chains are getting increasingly more complex, more extended, and more global. In general, the development and implementation of block chain solutions in supply chains are still at an early stage. Thus, there are many opportunities for companies in the future when the technology is further developed (Novinsky and Kozma, 2017).

Moreover, a theoretical insight is required to better understand the underlying motivators and barriers that will lead companies, or discourage them, from adopting block chain technologies for supply chain traceability. The development and use of Block chain technology may in time constitute the biggest change to this date in how one securely stores and share data. Therefore, adapting block chain technologies creates significant implications for corporations looking to meet the demands of the future. For instance, adopting a new way of storing your data requires a different skillset than what is already present in many companies, in terms of technological expertise (Alexandre Arnolado, 2018).

All in all, the results in this paper may give an indication as to whether developing countries corporations have adopted, or intend to adopt Block chain technology, and if so, what the most important drivers for adoption are. For those countries corporations it may be of importance to look at what factors affect the adoption of a new and disruptive technology, and as a result take action (Alexandre Arnolado, 2018). Therefore, this paper will commiserates how using the new theories and block chain technologies through the supply chain will affect it as a whole; in addition to Such adaptation very rare to be represented especially in developing countries as this part will be full filled by our paper research.

\section{Relation between T-O-E Model and Block Chain Adoption}

Uncertainty exists amongst IT leaders whether block chain might be an interesting technology to adopt for their organization. There are teams in large organizations, like banks and technology consultancy firms, devoted to discovering the potentials with this technology. Startups are also experimenting with the technology to find out what its use cases are. Hence the organization's mangers decided to have access to this knowledge, select whether they should start innovating with block chain technology or not.

In order to explain technology adoption, two models for the adoption of technological innovation are combined: The Technology-Organization-Environment (TOE) framework (DePietro, Wiarda \& Fleischer, 1990) and the Diffusion of Innovation (DOI) theory (Rogers, 1995). Where both these models have been used extensively to predict and explain adoption of several old other technologies, explore how to innovate but none of them try to choose for specific bossiness context to adopt Block chain technology yet.

Accordingly, this paper aims at filling this gap in the literature by making the first steps to defining a model tailored to the adoption of block chain technology. Moreover, in addition, this model adaptation can be used by bossiness organization mangers in various industries to review the arguments in favor and against the adoption of block chain technology in their organization. Therefore, this paper goal is to identify relevant theories for (TOE) Technology Organization Environment decide the significant importance of adopting block chain technology within their organization (Anders Tveita, 2018).

In view of that, the following new theories for the (TOE) model of block chain adoption were identified through iteratively coding data According to L'yan, (2017) as block chain experts: 
Regulatory Support: Compliance refers to the level of conformance to the rules and regulations, in this case prescribed by the government.

Security: referring to high level of secure data that transmit through the entire chain. This reflects that such adaption will help and improve the business organizations performance.

For that reason, regulatory support and security considers to be very vital factors in adapting Block chain technologies. Promoting new business direction and visions will create massive changes in business ecosystems.

\section{Block chain Adoption and Supply Chain Management}

Supply chain is considered as one of the industries where block chain has the biggest potential to disrupt. Several Sectors use block chain in supply chain management keeps increasing as the industry increasingly gains more awareness of the technology. Amongst other things, block chain can be used to improve contract management, improve supply chain and security, and create product attribution (Gammelgaard, 2019).

Block chain's relative benefit in supply chains through the way supply chains are managed is arguably ineffective when it comes to facilitating information sharing and coordinating the operations among involved entities (Dobrovnik, 2016). The time that must be devoted to solving a problem or untangling a specific communicative discrepancy will likely increase as the network grows.

Therefore, the main benefits of block chain in supply chain management can be classified into two major categories being either first, operational efficiencies, or second improving trust and security (Alexandre Arnolado, 2018). A block chain is not necessarily the right tool for all supply chains as the applicability depends on the level of complexity of the supply chain and the value created from increased visibility over the supply chain (Dobrovnik, 2016). While a block chain could potentially solve a large amount of supply chain challenges, one must evaluate whether the effects of block chain through adapting its technologies with regard to supply chain security.

Hence, it is important for managers to thoroughly understand their supply chain structure before considering implementing a block chain technologies solution. According to previous studies in line behind implementing a block chain can provide significant improvements and benefits to their supply chain (Gammelgaard, 2019). Highlighting on adapting such technology is not that easy. based on the several supply chain operations and processes, main challenges raise up which is the complexity referring to uncertainty that the block chain technology creates about the uses of the technology for the organization. One can reason that this is a form of technology complexity, because uncertainty leads to a lack of understanding, which leads to a more complex perception of the block chain technology (Anders Tveita, 2018).

Therefore, this paper empathizes how using the new theories and block chain technologies through the supply chain will affect it as a whole; in addition to Such adaptation is very rare to be represented especially in developing countries as this part will be full filled by our paper research. Reducing complexity and lowering supply chain investment costs associated with traditional supply chain transactions were some of the key drivers for block chain adoption, as well as a desire to benefit from enhanced security, efficiency, and transparency.

\section{Research Methodology}

In order to test the research hypotheses that under this study, the research methodology adopted is based on several issues as illustrated below:

Unit of Analysis: It is the step of gathering of the data collected for the purpose of the data analysis process. It is represented in employees of supply chain and logistics companies.

Population and Sample: The target population for this research is considered as the total number of employees of supply chain and logistics companies. Since obtaining data about all members of a population is not available and very difficult (Fowler, 2013), the sampling frame for this research could not be identified and accordingly a probability sampling is not obtained. Therefore, a convenient sampling technique was used as respondents were selected from supply chain and logistics companies who accepted to respond to the questionnaire. A total number of 427 were considered in the study after 
excluding questionnaire with missing responses. An almost equal number of respondents were collected from each company.

Data Collection: The data collection process is handled through the development of a questionnaire that allows for the measurement of how using the technological theories and block chain technologies through the supply chain will affect it as a whole. The adoption of this data collection method was due to the need to measure the focal constructs of the model, as well as the extensive use of survey methodology in previous studies. The questionnaire is shown in the Table 1, where a total number of 18 statements were defined for the research variables. The questionnaire was adopted from the studies of Gutierrez et al. (2015), Amini (2014), and Wangui (2018).

Research Framework and Hypotheses: The proposed framework was introduced in Figure 1, where it could be observed that Security, Regulatory Support, Competitive Pressure, Compatibility, and Complexity were considered as the independent variables, while, Adoption of Block chain is considered as the dependent variable. The variables: Complexity and Compatibility are considered as variables representing Technology; Competitive Pressure is considered as a variable representing Environment; Security and Regulatory Transport are considered as variables representing Organization. Therefore, the independent variables represent the TOE model dimensions, which might affect the Block Chain Adoption.

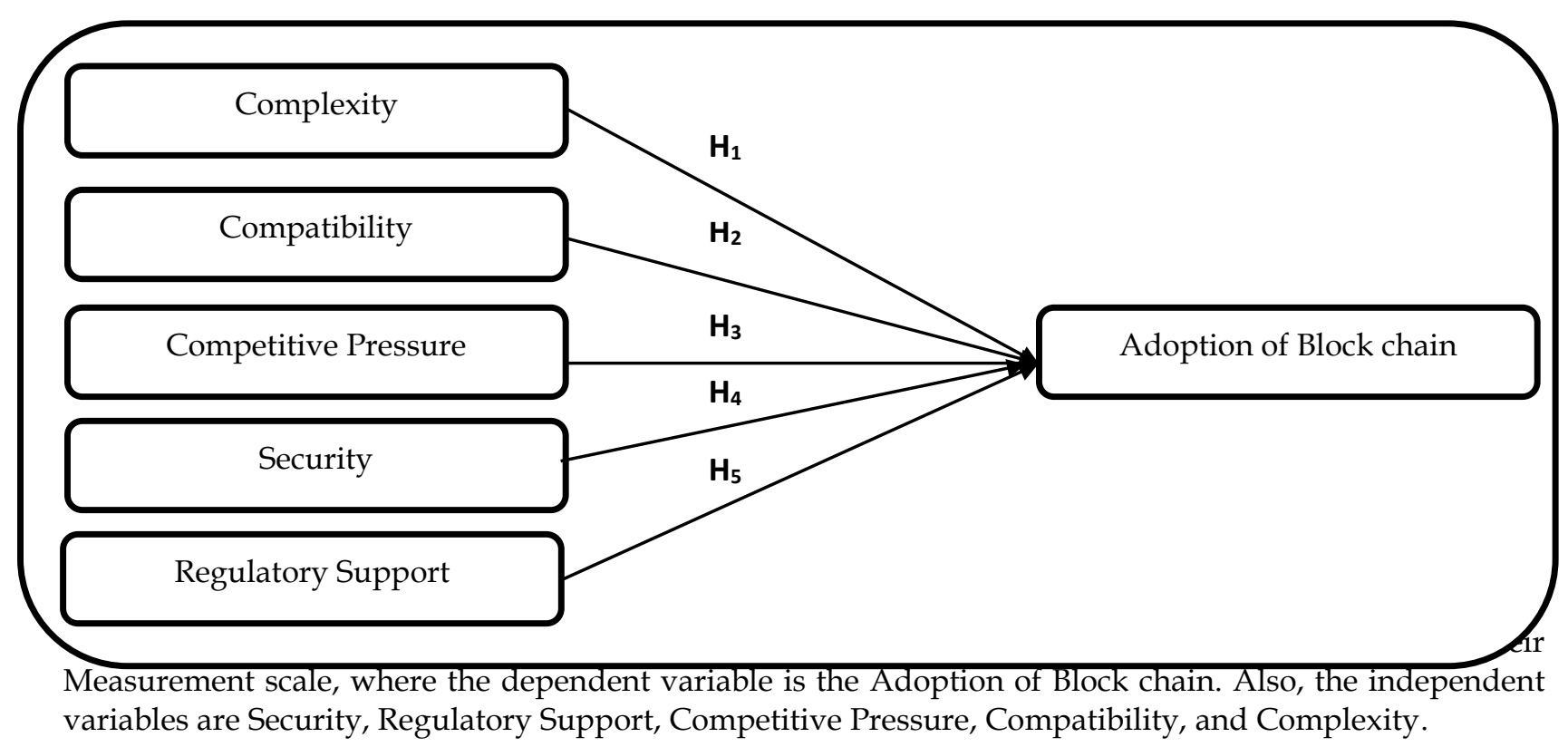

Table 1: Research Variables Measurement Scale

\begin{tabular}{|c|c|}
\hline Research Variables & Measurement Scale \\
\hline \multirow{3}{*}{$\begin{array}{l}\text { Complexity (Gutierrez et al., } \\
\text { 2015) }\end{array}$} & Block chain services are easy to integrate with existing processes \\
\hline & Confidence levels in block chain influence adoption decision \\
\hline & Block chain is easy to use and manageable \\
\hline \multirow{3}{*}{ Compatibility (Amini, 2014) } & The use of block chain fits the work style of the company \\
\hline & The use of block chain is fully compatible with current business operations \\
\hline & $\begin{array}{l}\text { The use of block chain will be compatible with existing hardware and software in } \\
\text { the company }\end{array}$ \\
\hline \multirow{3}{*}{$\begin{array}{l}\text { Competitive pressure (Amini, } \\
\text { 2014) }\end{array}$} & Firms think that block chain has an influence on competition in their industry \\
\hline & Some of our competitors have already started using block chain \\
\hline & Block chain would allow generation of higher profits \\
\hline \multirow{3}{*}{ Security (Amini, 2014) } & Degree of company's concern with data security on the block chain \\
\hline & Degree of concern for customers with data security in block chain \\
\hline & Degree of concern about privacy in block chain \\
\hline \multirow{2}{*}{$\begin{array}{l}\text { Regulatory Support (Amini, } \\
\text { 2014) }\end{array}$} & The laws that exist nowadays are sufficient to protect the use of block chain \\
\hline & The regulations that exist nowadays are sufficient to protect the use of block chain. \\
\hline
\end{tabular}




\begin{tabular}{|l|l|}
\hline Research Variables & Measurement Scale \\
\hline & There is legal protection in the use of block chain \\
\hline \multirow{3}{*}{$\begin{array}{l}\text { Adoption of Block chain } \\
\text { (Wangui, 2018) }\end{array}$} & $\begin{array}{l}\text { To what extent are you familiar with block chain adoptions in supply chain } \\
\text { management? }\end{array}$ \\
\cline { 2 - 2 } & $\begin{array}{l}\text { To what extent have you considered block chain applications in supply chain } \\
\text { management in your organization? }\end{array}$ \\
\cline { 2 - 2 } & $\begin{array}{l}\text { To what extent are you likely to adopt block chain applications in supply chain } \\
\text { management within the next 2 years? }\end{array}$ \\
\hline
\end{tabular}

The following section will investigate the research hypotheses proposed above using correlation analysis and Structural Equation Modeling (SEM). Thus, both; SPSS and AMOS statistical packages versions 24.

\section{Results and Findings \\ Data Testing}

Table 1 shows the Validity and Reliability analysis. It could be observed that the values of KMO, AVE, Cronbach's Alpha, and Factor Loading are within the acceptance level.

Table 2: Validity and Reliability Analysis

\begin{tabular}{|c|c|c|c|c|c|}
\hline Variables & $\mathrm{KMO}$ & AVE & Cronbach's Alpha & Items & Factor Loading \\
\hline \multirow{3}{*}{ Security } & \multirow{3}{*}{.736} & \multirow{3}{*}{$81.499 \%$} & \multirow{3}{*}{.885} & S1 & .775 \\
\hline & & & & S2 & .821 \\
\hline & & & & S3 & .849 \\
\hline \multirow{3}{*}{ Regulatory Support } & \multirow{3}{*}{.713} & \multirow{3}{*}{$73.637 \%$} & \multirow{3}{*}{.820} & RS1 & .695 \\
\hline & & & & RS2 & .749 \\
\hline & & & & RS3 & .765 \\
\hline \multirow{3}{*}{ Competitive Pressure } & \multirow{3}{*}{.717} & \multirow{3}{*}{$81.077 \%$} & \multirow{3}{*}{.883} & $\mathrm{CP} 1$ & .763 \\
\hline & & & & $\mathrm{CP} 2$ & .867 \\
\hline & & & & $\mathrm{CP} 3$ & .803 \\
\hline \multirow{3}{*}{ Compatibility } & \multirow{3}{*}{.710} & \multirow{3}{*}{$73.024 \%$} & \multirow{3}{*}{.815} & $\mathrm{Cm} 1$ & .770 \\
\hline & & & & $\mathrm{Cm} 2$ & .709 \\
\hline & & & & $\mathrm{Cm} 3$ & .712 \\
\hline \multirow{3}{*}{ Complexity } & \multirow{3}{*}{.734} & \multirow{3}{*}{$78.028 \%$} & \multirow{3}{*}{.859} & Cx1 & .781 \\
\hline & & & & $\mathrm{C} \times 2$ & .797 \\
\hline & & & & $\mathrm{C} \times 3$ & .763 \\
\hline \multirow{3}{*}{ Adoption } & \multirow{3}{*}{.727} & \multirow{3}{*}{$79.678 \%$} & \multirow{3}{*}{.872} & Ad1 & .743 \\
\hline & & & & Ad2 & .833 \\
\hline & & & & Ad3 & .814 \\
\hline
\end{tabular}

Table 2 shows the discriminant validity of the research variables, where it could be observed that all square root values of AVE are greater than the correlations between the corresponding construct and other constructs. This means that the research variables have adequate discriminant validity.

Table 3: Discriminant Validity of the Research Variables

\begin{tabular}{|c|c|c|c|c|c|c|}
\hline & 1. & 2. & 3. & 4. & 5. & 6. \\
\hline \multirow[t]{3}{*}{ Security } & $(0.903)$ & & & & & \\
\hline & & & & & & \\
\hline & 427 & & & & & \\
\hline \multirow[t]{3}{*}{ Regulatory Support } & $.173^{\text {** }}$ & $(0.858)$ & & & & \\
\hline & .000 & & & & & \\
\hline & 427 & 427 & & & & \\
\hline \multirow[t]{3}{*}{ Competitive Pressure } & $.469^{* *}$ & $.381^{* *}$ & $(0.900)$ & & & \\
\hline & .000 & .000 & & & & \\
\hline & 427 & 427 & 427 & & & \\
\hline \multirow[t]{3}{*}{ Compatibility } & $.184^{* \star}$ & $.245^{* *}$ & $.336^{\text {*t }}$ & $(0.855)$ & & \\
\hline & .000 & .000 & .000 & & & \\
\hline & 427 & 427 & 427 & 427 & & \\
\hline \multirow[t]{2}{*}{ Complexity } & $.371^{* *}$ & $.283^{* *}$ & $.534^{\text {*t }}$ & $.303^{* *}$ & $(0.883)$ & \\
\hline & .000 & .000 & .000 & .000 & & \\
\hline
\end{tabular}




\begin{tabular}{|l|l|l|l|l|l|l|}
\hline & 427 & 427 & 427 & 427 & 427 & \\
\hline Adoption & $.501^{\text {** }}$ & $.431^{\text {** }}$ & $.543^{\text {** }}$ & $.393^{\text {** }}$ & $.443^{\text {** }}$ & $(0.893)$ \\
\cline { 2 - 8 } & .000 & .000 & .000 & .000 & .000 & \\
\cline { 2 - 7 } & 427 & 427 & 427 & 427 & 427 & 427 \\
\hline
\end{tabular}

\section{Descriptive Analysis}

Table 3 shows the Mean and Standard Deviation for Research variables. It could be observed that the mean and the frequencies of most responses are in the agreement zone, as the mean values for the research variables: Security, Regulatory Support, Competitive Pressure, Compatibility, Complexity, and Adoption are 3.8150, 3.8970, 3.8806, 4.0749, 3.9789, and 3.9766.

Table 4: Descriptive Analysis for the Research Variables

\begin{tabular}{|c|c|c|c|c|c|c|c|c|}
\hline & & & & & en & & & \\
\hline & $\mathbb{N}$ & Mean & Std. Deviation & 1 & 2 & 3 & 4 & 5 \\
\hline Security & 427 & 3.8150 & 66499 & 0 & 0 & 141 & 224 & 62 \\
\hline Regulatory Support & 427 & 3.8970 & .56806 & 0 & 0 & 93 & 285 & 49 \\
\hline Competitive Pressure & 427 & 3.8806 & 63709 & 0 & 0 & 115 & 248 & 64 \\
\hline Compatibility & 427 & 4.0749 & 61209 & 0 & 0 & 65 & 265 & 97 \\
\hline Complexity & 427 & 3.9789 & 71669 & 0 & 0 & 114 & 208 & 105 \\
\hline Adoption & 427 & 3.9766 & 67094 & 0 & 0 & 101 & 235 & 91 \\
\hline
\end{tabular}

\section{Testing the Research Hypotheses}

Table 4 shows the regression model fitted for the effect of Independent Variables, Security, Regulatory Support, Competitive Pressure, Compatibility, and Complexity on Adoption. It could be noted that there is a significant positive effect of the Independent Variables on Adoption as the regression coefficients are $0.297,0.271,0.209,0.201$, and 0.101 respectively and P-values are less than 0.000 . Moreover, the $\mathrm{R}$ square is 0.473 which means $47.3 \%$ of the variation of the Adoption can be explained by the independent variables together. The research variables importance with respect to Adoption could be ranked as follows: firstly, Security with a Standardized Coefficients of 0.294 , secondly, Regulatory Support with a Standardized Coefficients of 0.229, thirdly, Competitive Pressure with a Standardized Coefficients of 0.198 , fourthly, Compatibility with a Standardized Coefficients of 0.183 , fifthly, Complexity with a Standardized Coefficients of 0.108 .

Table 5: Regression Model of Independent Variables on Adoption

\begin{tabular}{|c|c|c|c|c|c|c|}
\hline \multirow[t]{2}{*}{ Model } & \multicolumn{2}{|c|}{$\begin{array}{l}\text { Unstandardized } \\
\text { Coefficients }\end{array}$} & \multirow{2}{*}{\begin{tabular}{|l}
$\begin{array}{c}\text { Standardized } \\
\text { Coefficients }\end{array}$ \\
Beta \\
\end{tabular}} & \multirow[t]{2}{*}{$\mathrm{t}$} & \multirow[t]{2}{*}{ Sig. } & \multirow[t]{2}{*}{ R Square } \\
\hline & $\mathrm{B}$ & Std. Error & & & & \\
\hline (Constant) & -.241 & .227 & & -1.060 & .290 & \multirow{6}{*}{.473} \\
\hline Security & .297 & .041 & 294 & 7.254 & .000 & \\
\hline Regulatory Support & .271 & .046 & .229 & 5.911 & .000 & \\
\hline Competitive Pressure & .209 & .049 & .198 & 4.221 & .000 & \\
\hline Compatibility & .201 & .042 & .183 & 4.789 & .000 & \\
\hline Complexity & .101 & .040 & .108 & 2.500 & .013 & \\
\hline
\end{tabular}

Table 5 shows the SEM analysis of the effect of Independent Variables, Security, Regulatory Support, Competitive Pressure, Compatibility, and Complexity on Adoption. It could be observed that there is a significant positive effect of the Independent Variables on Adoption as the regression Estimates are $0.204,0.249,0.189,0.198$, and 0.130 respectively and P-values are less than 0.000 . Moreover, the $\mathrm{R}$ square is 0.523 which means $52.3 \%$ of the variation of the Adoption can be explained by the independent variables together. 
Table 6: SEM Analysis of the Effect of Independent Variables on Adoption

\begin{tabular}{|l|l|l|l|l|l|}
\hline & & & Estimate & $\mathrm{P}$ & $\mathrm{R}^{2}$ \\
\hline Adoption & $<---$ & Security & .204 & $* * *$ & \\
\hline Adoption & $<---$ & Regulatory Support & .249 & $* * *$ & \multirow{2}{*}{.523} \\
\hline Adoption & $<---$ & Competitive Pressure & .189 & $* * *$ & \\
\hline Adoption & $<---$ & Compatibility & .198 & $* * *$ & \\
\hline Adoption & $<---$ & Complexity & .130 & .006 & \\
\hline
\end{tabular}

The model fit indices are presented in Table 8 which could be observed that are all within their acceptable levels. The SEM model conducted for the effect of Independent Variables on Adoption is illustrated in Figure 1.

Table 7: The Model Fit Indices

\begin{tabular}{|l|l|l|l|l|}
\hline CMIN/DF & RMSEA & CFI & GFI & AGFI \\
\hline 1.073 & .013 & .998 & .969 & .956 \\
\hline
\end{tabular}

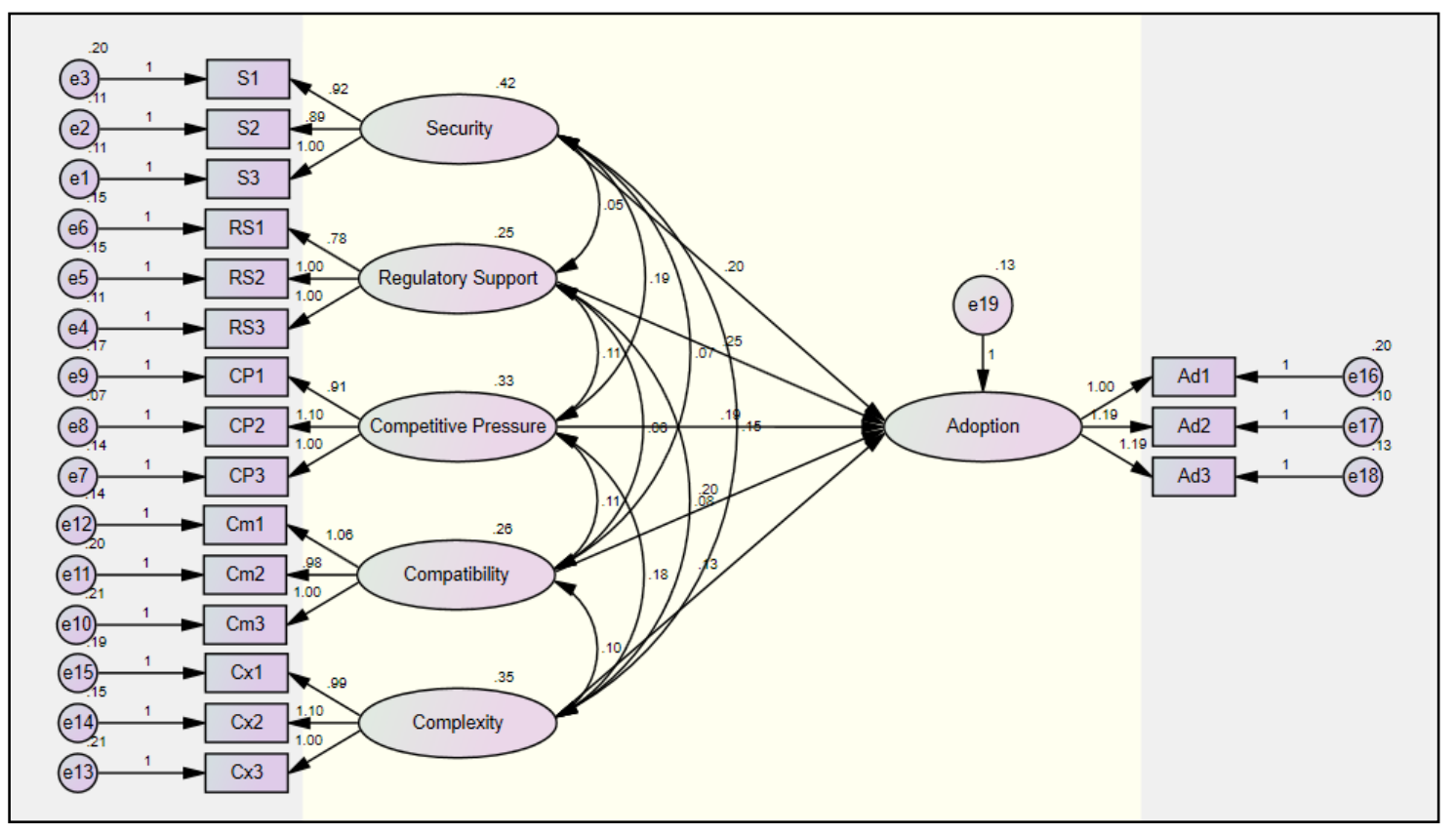

Figure 2: SEM Analysis of the Effect of Independent Variables on Adoption

\section{Discussion and Conclusion}

This research provides an insight to understand the significant dimensions of block chain adoption, where the dimensions of security, regulatory support, competitive pressure, compatibility, and complexity are found to have a significant effect on block chain adoption. This result is consistent with the results observed by Novinsky and Kozma (2017) as well as Arnolado (2018).

It was observed that Security comes as the most important factor for block chain adoption, as the corresponding standardized coefficient is the highest (0.294), which is consistent with Arnolado (2018). The second important factor for block chain adoption is regulatory support, with a standardized coefficient of 0.229 , which is consistent with the results of Dobrovnik (2016). The third one is the competitive pressure, with a standardized coefficient of 0.198 . This is the same result obtained by Tveita (2018).

It should also be noticed that all the dimensions under study were found to have a significant effect on block chain adoption, indicating that all the research variables are considered important for the block chain adoption. The results obtained is consistent with that obtained by DePietro et al. (1990).

www.jbrmr.com A Journal of the Centre for Business \& Economic Research (CBER) 


\section{References}

Alexandre Arnolado, A. B. (2018). An exploaration of BlockChain TEchnology in Supply Chain Management. Research Gate, 13.

Amini, M., (2014). The factors that influence on adoption of cloud computing for small and medium enterprises.

Anders Tveita, M. B. (2018). The Adapation Of Block Chain Technology In NOrwegian Corporations. International School of Ecnomics Schools , 101.

Dobrovnik, M. (2016). Block Chain for and in Logistics : What to adapt and where to start. MDPI, 23.

Fowler Jr, F.J., (2013). Survey research methods. Sage publications.

Gutierrez, A., Boukrami, E. and Lumsden, R., 2015. Technological, organizational, and environmental factors influencing managers' decision to adopt cloud computing in the UK. Journal of Enterprise Information Management, 28(6), pp.788807.

Gammelgaard, B. (2019). Block Chain Technology Chains . Samarbedje med bussines school , 39.

Wangui, R., (2018). Perception of Procurement Professionals on the Adoption of Block chain Technologies and Its Impact on Supply Chain Management in Kenya. 